\title{
O Mercosul e a Nova Ordem Econômica Internacional
}

\section{ALAN BARBIERO* e YVES CHALOULT**}

Em 1991, ano em que surge o Mercosul, o mundo já vivia sob o impacto da globalização e da regionalização. À época no entanto, esses dois fenômenos, embora não fossem recentes, ainda desconheciam a intensidade com que hoje se apresentam, menos de uma década depois.

Com efeito, a partir dos anos 90 a globalização se viu impulsionada por um cenário político internacional que não mais encontrava os antigos obstáculos colocados pela Guerra Fria; sem falar no enorme avanço tecnológico da informática e dos meios de comunicação e de informação, que vêm revolucionar a relação tempo-espaço no mundo contemporâneo. Por sua vez, a regionalização tem assistido a um processo de multiplicação dos acordos de integração regional por todo o mundo, sendo que, somente no período de 1992 a 1996, foram registrados no Acordo Geral sobre Tarifas Aduaneiras e Comércio (Gatt) cerca de 30 acordos bilaterais, sub-regionais ou regionais.

Uma análise do Mercosul à luz da evolução desses dois movimentos é o que intentamos nestas linhas. Qual foi o contexto internacional que possibilitou o surgimento do Mercosul? Que condições sócio-econômicas presentes na América Latina favoreceram a sua formação? Como evoluíram as propostas de regionalismo econômico? Que propósitos e influências marcaram a definição do modelo de integração do Mercosul?

Na tentativa de resposta a essas perguntas, inicialmente é debatido o conceito de globalização com base em elementos extraídos da leitura de diversos autores. Adiante-se que compartilhamos da idéia de que a globalização não está formando uma sociedade homogênea, apesar de implantar, como nunca na história da humanidade, uma ordem econômica de amplitude mundial. Na seqüência, são expostas algumas noções básicas, mas substanciais, para a compreensão do que estamos chamando de regionalização. Finalmente, numa abordagem históricoanalítica que remonta à ordem econômica que emerge após a Segunda Guerra Mundial, é desenhado o contexto internacional em que surge o Mercosul. 
O objetivo principal é compreender o contexto mundial e a nova ordem internacional que possibilitaram a criação do Mercosul, assim como as condições que favoreceram a definição de seu modelo. No desenvolvimento da análise, a globalização, embora seja vista como um processo multidimensional, é considerada principalmente em sua dimensão econômica.

\section{Um conceito em construção}

Embora o termo globalização não possa ser considerado ainda um conceito preciso, correspondendo a uma realidade empírica inequivocamente descrita na literatura, há um relativo consenso entre os estudiosos das ciências sociais e econômicas de que o mesmo está associado às mudanças significativas que vêm ocorrendo nas relações políticas, econômicas, sociais e culturais do mundo contemporâneo.

Para Giddens (1991), a globalização poderia ser melhor conceituada se os sociólogos, em vez de darem uma importância indevida à idéia de sociedade, no que ela significa um sistema limitado, a substituíssem por um ponto de partida que se concentrasse em analisar como a vida social é ordenada através do tempo e do espaço - na problemática do distanciamento tempo-espaço. Assim, a estrutura conceitual do distanciamento tempo-espaço dirige nossa atenção às complexas relações entre envolvimentos locais e interação à distância. "O nível de distanciamento tempo-espaço na era moderna é muito maior do que em qualquer outro período precedente, e as relações entre formas sociais e eventos locais e distantes se tornam correspondentemente 'alongadas'. A globalização se refere essencialmente a este processo de alongamento, na medida em que as modalidades de conexão entre diferentes regiões ou contextos sociais se enredam através da superfície da Terra como um todo” (Giddens, 1991:69-70). Portanto, para esse autor, a globalização pode ser definida como a intensificação das relações sociais em escala mundial, ligando localidades distantes de tal maneira que acontecimentos locais são modelados por eventos ocorrendo a grandes distâncias e vice-versa.

Por seu turno, Santos (1997) distingue quatro constelações de relações sociais que designa de "espaços-tempo estruturais": o espaço-tempo doméstico, o espaço-tempo da produção, o espaço-tempo da cidadania e o espaço-tempo mundial. Segundo ele, a problematicidade do tempo presente não advém de nenhuma dessas constelações em separado, mas de sua conjunção. No entanto, é óbvio que o espaçotempo mundial, que tem uma maior influência sobre os demais, vem aumentando sua relevância em virtude da intensificação da globalização da economia e das interações transnacionais em geral nas duas últimas décadas. Seu problema fundamental refere-se à crescente polarização entre o Norte e o Sul, ou seja, à existência de desigualdades dentro do sistema mundial. 
Apesar de coerente ao analisar as desigualdades mundiais a partir da divisão entre Norte e Sul, a abordagem de Santos talvez não seja a mais adequada para a conjuntura atual. Dividir o mundo entre Norte rico e Sul pobre parece-nos uma simplificação que sombreia a complexidade dos conflitos e a heterogeneidade do mundo contemporâneo. Compreender o processo de globalização exige também compreender o comportamento das diferentes matrizes culturais: como estas reagem àquela?

É certo que, segundo Ortiz (1996), muitos signos, símbolos, emblemas, figuras ou ídolos circulam e flutuam pelo mundo desterritorializados. Porém, não podemos imaginar que a sua apropriação pelas diferentes culturas se dê de forma similar.

A circulação desses signos e símbolos, produzidos geralmente pelo Ocidente e propagados por todo o mundo através dos canais de comunicação, cria uma situação de ambigüidade: ao mesmo tempo em que alguns valores se tornam universais, as diversidades de valores emergem de maneira substancial. Para Featherstone (1996), a velocidade e a expansão dos meios de comunicação, embora não assegurem condições igualitárias de participação, permitem que novos atores entrem no jogo e reivindiquem o direito de ser ouvidos, ainda mais com a facilidade do transporte-transmissão de pessoas, imagens e objetos através do mundo inteiro e com o conseqüente aumento das dificuldades dos governos para vigiar e controlar o volume de informação e imagens que atravessam suas fronteiras. Assim, o processo de globalização não somente favorece o aparecimento de uma cultura global unificada, mas, sobretudo, tende a promover um campo de fragmentação, sincretismo e hibridização das culturas. Em suma, ele revela a natureza multiforme e a extrema complexidade dos fenômenos culturais.

Por ser a identidade cultural ou étnica contrastiva, ou seja, ela se realça quando em contato com outra, num mundo globalizado e heterogêneo, com forte preponderância dos valores ocidentais, o contato entre as diferentes identidades reforça as identidades em si, provocando muitas vezes uma reação de oposição àqueles valores colocados como paradigmáticos pelo bloco que procura manter sua hegemonia mundial.

Nesse sentido, a análise de Santos deve ser enriquecida pela abordagem desenvolvida por Huntington (1997) em sua obra O choque de civilizações. Huntington afirma que a modernização econômica e social não está produzindo nem uma civilização universal significativa, nem a ocidentalização das sociedades não-ocidentais. Os conflitos mais abrangentes e importantes do futuro não se definirão entre ricos e pobres, ou grupos definidos em termos econômicos ou ideológicos, e sim entre identidades culturais diferentes, ou seja, entre civilizações ${ }^{1}$.

Dentro desta perspectiva, o processo de globalização muda radicalmente o contexto da política contemporânea, transformando suas condições, conseqüências e atores, que por sua vez expandem o horizonte de ação - sentidos, valores, 
constituição de sujeitos e de identidades, alianças e antagonismos - e interpelam as categorias com que habitualmente são pensados seus principais problemas, dilemas e desafios (Gómez, 1997).

É importante ressaltar no entanto que, para qualquer abordagem consistente sobre o processo de globalização, deve-se tomar o cuidado de não cair na ideologização ou mitificação do termo. Chesnais (1996), por exemplo, alerta-nos sobre a popularização das expressões global e globalização no discurso político neoliberal, muitas vezes com uma conotação ideológica, quando na verdade esses termos são ainda vagos e ambíguos.

Hirst e Thompson (1998), buscando desmistificar alguns aspectos do processo de globalização, defendem a tese da possibilidade de governabilidade nacional e internacional no mundo contemporâneo. Para eles, a atual economia, altamente internacionalizada, tem precedente, sendo uma das diversas conjunturas ou estados da economia internacional que existiram desde a segunda metade do século XIX. Sob certos aspectos, a economia internacional contemporânea é menos aberta e integrada do que o regime que prevaleceu de 1870 a 1914 . A mobilidade do capital não está produzindo uma transferência maciça de investimentos e de empregos dos países avançados para os países em desenvolvimento. Contrariamente ao que pensam alguns defensores extremados da globalização, a economia mundial está longe de ser global; os fluxos de comércio, investimento e capital financeiro estão concentrados na Tríade formada pela Europa, Japão e América do Norte. Os mercados globais estão fora da regulação e do controle, ainda que o alcance atual e os objetivos da governabilidade econômica sejam limitados pelos interesses divergentes das grandes potências e pelas doutrinas econômicas que prevalecem entre suas elites.

Em síntese, sendo as características mais visíveis da globalização a compactação espacial, a aceleração temporal e a produção de novas heterogeneidades, produzidas em - e dando origem a - contextos sócio-naturais de alta incerteza (Dreifuss, 1997), os seus diversos vetores podem ser contraditórios e abertos a vários desdobramentos, às vezes conflitantes entre si. A globalização se mostra assim como um processo complexo e multidimensional que guarda não poucas ambigüidades. Daí em seu estudo impor-se a consideração da ambivalência como uma importante categoria sociológica ou mesmo uma questão metodológica, pois conforme alerta Beck (1997:22) "as categorias e os métodos da ciência social falham diante da vastidão e da ambivalência dos fatos que devem ser apresentados e considerados".

\section{Elementos sobre a regionalização}

O regionalismo econômico internacional é, junto com a globalização dos mercados, um dos traços mais marcantes da economia mundial do Pós-guerra. 
Percebe-se uma estreita relação entre a crise de legitimidade que atravessam atualmente as grandes instituições econômicas internacionais e a proliferação de acordos comerciais de várias ordens nos últimos 10 anos $^{2}$. Os países são levados a renovar suas formas de cooperação, estreitando-as em escala internacional nos processos integrativos (Deblock e Brunelle, 1996). Isto nos faz interrogar sobre a natureza desse fenômeno que tomou importância tanto por sua amplitude como pelo interesse que suscita em todas as partes do mundo.

Para Oman (1994), o movimento atual de regionalização responde em parte à globalização econômica. Esses dois processos se opõem na medida em que o primeiro é um movimento essencialmente centrípeto e político, ao passo que o segundo é centrífugo e corresponde a um fenômeno microeconômico resultante principalmente do comportamento e das estratégias das empresas transnacionais. Mas nem por isso um e outro são antitéticos ou antagônicos. Antes, dado que a regionalização contribui na consolidação do jogo da concorrência, os dois processos tendem mais a se reforçar do que a se contrapor.

Se num primeiro momento as trocas comerciais predominam, a evolução do processo de integração pode levar a sua ampliação para outros setores. Como afirmam Deblock e Brunelle (1996), quaisquer que sejam as motivações de ordem econômica que animam os atores estatais, os acordos regionais sempre responderam a propósitos que vão além da esfera estritamente econômica, sobretudo quando têm por objetivo a criação de blocos econômicos. Dizendo de outra forma, nenhum acordo econômico regional jamais respondeu a preocupações de natureza exclusivamente econômica.

A integração regional pode ser vista como uma passagem para uma nova estrutura organizacional dos Estados-nações, na qual novas formas de relacionamento interno e externo surgem formalizando um novo espaço comum o espaço integrado. Como conseqüência, modifica-se radicalmente a concepção do interno e do externo, chegando-se a um novo marco: as fronteiras do espaço comum ampliado. A integração entre Estados nacionais implica um processo de inter-relacionamento e interdependência multidimensional que obriga a ter presentes, simultaneamente, diferentes planos da realidade social (Fernández, 1992).

Vários autores assinalam as condições (Galtung, 1968), potencialidades (Nye, 1971) ou pressupostos (Errandonea, 1977) para a integração entre Estados nacionais. Embora nenhum afirme que qualquer desses fatores seja necessário ou suficiente para o sucesso da integração regional, eles acreditam que a presença de determinadas condições favorecem o desenvolvimento de redes de interdependência que facilitam a transferência de lealdade do plano nacional para o supranacional. Algumas delas são: (1) a existência de um substrato comum de valores e interesses e, mais importante ainda, de uma escala de preferências bem estabelecida entre eles, de modo que conflitos e dilemas possam ser mais facilmente resolvidos; (2) uma relativa simetria econômico-social e político-institucional, com 
certo grau de complementaridade entre os Estados envolvidos, condição para que se amplie a interdependência; (3) a complementaridade e consistência dos valores e interesses manifestos e compartilhados pelas elites dos atores envolvidos; (4) o apoio e o compromisso de cada Estado nacional à associação supranacional, contando com atores políticos capazes de assumir as tarefas da integração com continuidade, competência e flexibilidade.

Existe uma dificuldade básica para qualquer tipo de integração, seja para as organizações políticas e de segurança ou para as organizações econômicas: a convergência e a comunhão de valores culturais. "As regiões são a base para a cooperação entre os Estados, unicamente na medida em que a geografia coincida com a cultura. Divorciada da cultura, a proximidade não gera por si só aspectos em comum e pode mesmo induzir exatamente o oposto" (Huntington, 1997:161). Desta forma, as alianças militares e as associações econômicas requerem a cooperação entre seus membros; a cooperação depende da confiança e a confiança brota mais facilmente de valores e cultura em comum.

Com várias experiências espalhadas pelo mundo, o processo de integração regional se dá em diferentes modelos, que podem ser ou não fases sucessivas da integração, a saber: zona de preferência tarifária, zona de livre comércio, união aduaneira, mercado comum e união econômica. O Mercosul é um projeto de construção de um Mercado Comum, cuja execução encontra-se na fase de União Aduaneira parcial ${ }^{3}$.

No interior das Américas podemos encontrar quatro grandes tipos de acordos comerciais:

1) quatro uniões aduaneiras: o Mercosul (ao qual são associados o Chile e a Bolívia), a Comunidade Andina, o Mercado Comum da América Central (MCAC) e o Mercado Comum do Caribe (Caricom);

2) acordos de livre comércio, como o Acordo de Livre Comércio da América do Norte (Nafta) e o Acordo entre o Grupo dos Três (Colômbia, México e Venezuela), além de múltiplos acordos bilaterais assinados, por exemplo, entre o México e o Chile, o México e a Costa Rica, o Canadá e o Chile etc.;

3) acordos preferenciais, dentre os quais o acordo Canadá-Caraíbas (Caribcan) e o entre os Estados Unidos (EUA) e os países da Comunidade Andina, cujo objetivo, dentre outros, é lutar contra o narcotráfico;

4) acordos de caráter mais geral, como a Associação Latino-Americana de Integração (Aladi), os acordos de complementação assinados no interior da Aladi e os diversos acordos de cooperação em matéria de comércio e investimento (Canadá e Estados Unidos, principalmente), ou ainda os acordos mais setoriais ou mais técnicos. 


\section{Inter-relações entre a globalização e a regionalização}

Discutido o conceito de globalização e vistas algumas noções sobre regionalização, podemos agora enfocar esses dois fenômenos e apontar as suas inter-relações. Em nossa abordagem procuraremos sublinhar o aspecto da historicidade e da complementaridade entre os dois movimentos, bem como evidenciar as heterogeneidades existentes e, ainda, levar em conta as preocupações estratégicas diferentes que podem motivar os diversos atores envolvidos. Conforme já advertimos, a globalização, embora constituída de múltiplas dimensões interrelacionadas (Viola e Oliveira, 1997), será considerada sobretudo em sua dimensão econômica, haja vista sua relação intrínseca com o surgimento do Mercosul.

Segundo Brunelle e Deblock (1996) ${ }^{4}$, a idéia de globalização econômica inscreve-se dentro de uma perspectiva histórica marcada por dois momentos fundamentais: (1) a implantação no Pós-guerra de uma nova ordem mundial baseada numa matriz liberal cujo principal arquiteto foi John Maynard Keynes, e (2) o fim da Guerra Fria, que abriu às empresas multinacionais a possibilidade de um papel mais relevante na liderança do processo de globalização econômica. O mesmo pode-se dizer da regionalização, daí sermos levados a dissociar o regionalismo atual, qualificado por esses autores como sendo de segunda geração, do regionalismo que o precedeu, ou seja, de primeira geração.

Desfaz-se dessa maneira a percepção de uma certa homogeneidade dentro dos acordos estabelecidos pertencentes a uma mesma categoria. Em outras palavras isso quer dizer que, mesmo tratando-se de dois acordos de livre comércio, ou de duas uniões aduaneiras, eles podem diferenciar significativamente entre si: uns podem se aproximar de um regionalismo de primeira geração e outros, de segunda. Observa-se, assim, uma descontinuidade nos processos de regionalização marcada principalmente pelas transformações impostas pela globalização econômica. Para compreender melhor isto, nos reportaremos inicialmente à ordem internacional que emerge nos anos 40 .

\subsection{Uma nova ordem mundial}

A construção da ordem do Pós-guerra se fez em dois níveis: nacional e internacional. Os Estados afetados diretamente pela Segunda Guerra Mundial se dedicaram à reconstrução ou à reconversão de sua economia nacional. Sobre a influência principal de Keynes, assiste-se à transformação do modo de regulação social e econômico dos Estados a partir da construção do que se chamou de providencialismo ${ }^{5}$. Esta iniciativa requer uma colaboração estreita entre três atores no plano nacional: o Estado, as organizações patronais e os sindicatos de trabalhadores. O compromisso entre tais atores, comumente chamado de tripartismo, foi essencial para a estabilidade da ordem do Pós-guerra. 
Em nível internacional a influência teórica de Keynes (1978) foi também marcante. O economista inglês tornou-se o grande arquiteto da nova ordem econômica mundial que emerge na década de 1940. Inspirada em suas idéias, a Organização das Nações Unidas (ONU) surge com um funcionamento calcado numa concepção moderna do papel do Estado. A ONU se coloca como uma organização compromissada em garantir uma visão universalista e pluralista da ordem internacional.

Talvez seja Shotwell (1945), em seu livro La grande décision, um dos que mais claramente expuseram a proposta de criação da ONU. Shotwell estava preocupado em estabelecer instrumentos capazes de evitar novos confrontos mundiais, buscando assim organizar uma comunidade internacional.

A proposta das Nações Unidas, segundo ele, tentava cobrir três grandes problemas: segurança, bem-estar e justiça. Para cada um, dever-se-ia empregar uma técnica diferente. Para o problema da segurança, a "action de police et l'emploi de la force”; para o bem-estar, a criação “d’un mécanisme de coopération”; e, para a justiça, uma expressão dentro de "une loi et une procédure internationales" (Shotwell, 1945:37). Na verdade, estavam aí lançadas as bases para a construção da nova ordem mundial.

Essa ordem se orientava em uma matriz liberal. Entretanto, é importante ressaltar que existiam divergências entre os liberais da época. Alguns propugnavam o intervencionismo por parte do Estado, já outros defendiam o não intervencionismo. O encontro dos liberais em Lippmann, em 1938, foi um dos momentos culminantes no acirramento das divergências entre os intervencionistas e os nãointervencionistas. Liderados por Keynes, os liberais partidários da primeira tendência formaram uma maioria. O economista Friedrich Hayek passará a ser, nos anos 40, um forte crítico de Keynes, representando os liberais da segunda tendência. Contudo, somente nos anos 70 é que Hayek, um dos principais representantes do neoliberalismo, exercerá uma ascendência teórica maior, enquanto a ordem econômica internacional seria marcada, em seus primórdios, pela influência dos liberais intervencionistas.

Os Aliados, ao formularem uma nova ordem econômica internacional, tinham como objetivo geral colocar o mundo fora do perigo da necessidade e da insegurança. O alcance desse objetivo passava por dois níveis. No primeiro, o Estado aparecia como o principal ator para garantir o progresso econômico e social; no segundo, buscava-se a criação de um sistema organizado de instituições econômicas internacionais, oriundas do sistema geral das Nações Unidas. O sistema implantado em nível econômico deveria ser complementar ao organizado para assegurar a paz. Fosse de forma individual ou coletiva, ele deveria também engajar o conjunto das nações, independentemente de seus regimes econômicos e políticos, na construção de uma ordem na qual esperava-se garantir a segurança e a prosperidade mutuamente. 
As instituições internacionais deveriam ter como tripé de sustentação o universalismo, a diferenciação e o tripartismo. Ao mesmo tempo em que deveriam ser considerados como iguais (idéia do universalismo), os países deveriam ter responsabilidades diferentes dentro da ordem internacional (princípio da diferenciação). Com referência ao tripartismo, Shotwell propõe o modelo da Organização Internacional do Trabalho (OIT) como sendo o mais indicado para todas as organizações internacionais, visto que envolve outros atores sociais na garantia do bem-estar. “C’est pourquoi nous avons suggéré ci-dessus que la constitution de cet organisme (l'OIT) soit étudiée pour servir de modèle à celle des organes autonomes qui seront nécessaires à la vie propre de l'économie internationale" (Shotwell, 1945:222).

Entretanto, o tripartismo será aplicado mais em nível nacional, pelo Estado providência, do que em nível internacional. Buscava-se com isto desenvolver a cooperação e a solidariedade dos principais atores na reconstrução da economia nacional, como também servir de contrapeso às idéias socialistas que ganhavam força na Europa do Pós-guerra. No plano internacional, a ONU criará o Conselho Econômico e Social (Ecosoc), inspirado no tripartismo, com a incumbência de promover a prosperidade na comunidade internacional emergente ${ }^{6}$. É importante assinalar que houve uma forte complementaridade entre a questão nacional e a internacional na construção dessa nova ordem mundial.

A Conferência de Bretton Woods, realizada nos EUA em 1944, deu origem ao Banco Internacional para a Reconstrução e Desenvolvimento (Bird) e ao Fundo Monetário Internacional (FMI), além de ter desencadeado o processo de implantação de várias outras instituições internacionais, como a Organização para a Alimentação e Agricultura (FAO) e a Organização das Nações Unidas para a Educação, a Ciência e a Cultura (Unesco). Foi ela importante não só para definir o quadro internacional em seu conjunto, mas também para determinar a posição da América Latina neste novo contexto, conforme se verá adiante

Do ponto de vista comercial, a economia internacional deveria liberalizarse. As barreiras tarifárias teriam de ser reduzidas em favor do comércio mundial. Para normatizar a redução das barreiras (ou mesmo suprimi-las) e dar peso ao livre comércio, criou-se, em 1947, o Acordo Geral sobre Tarifas Aduaneiras e Comércio (Gatt), fechando o quadro da nova ordem mundial ${ }^{7}$.

Contudo, a ordem mundial concebida no Pós-guerra não foi totalmente efetivada. Conforme assinala Hobsbawm (1999:224), “a Segunda Guerra Mundial mal terminara quando a humanidade mergulhou no que se pode encarar, razoavelmente, como a Terceira Guerra Mundial, embora uma guerra muito particular”. Não foi criada uma comunidade verdadeiramente internacional, mas um mundo marcado pela bipolaridade entre os países capitalistas de um lado, liderados pelos EUA, e os socialistas de outro, tendo a União Soviética à sua frente. Somente em 1989, com a queda do muro de Berlim, a subseqüente 
desintegração do bloco soviético e o fim do socialismo real, o quadro idealizado seria então implantado, mas não sem alterações para se adequar à conjuntura atual. O fim da Guerra Fria "retirou de repente os esteios que sustentavam a estrutura internacional e ... as estruturas dos sistemas políticos internos mundiais" (Hobsbawm, 1999:251). Se antes as empresas múlti ou transnacionais encontravam um obstáculo para atuarem mundialmente, elas agora estão livres para liderarem o processo de globalização econômica. Isto influenciará, sobremaneira, nos modelos de regionalismo econômico.

\subsection{A evolução do regionalismo econômico}

O regionalismo econômico implantado no Pós-guerra se desenvolveu em paralelo com o sistema multilateral do Gatt, inscrevendo-se num contexto internacional particular marcado, de um lado, pela Guerra Fria e, de outro, pelas frustrações em face da lentidão na edificação de uma ordem verdadeiramente internacional.

O Plano Marshall de 1947 exigia, em contrapartida à ajuda financeira oferecida, que os países europeus destruídos pela guerra deveriam reagrupar-se e dotar-se de instituições comuns. Impulsionada por esse plano, a Organização Européia de Cooperação Econômica (Oece) ${ }^{8}$ foi criada em 1948, podendo ser considerada como uma das primeiras grandes organizações econômicas regionais do Pós-guerra. Explicitamente, ela respondia a preocupações de ordem geopolítica e econômica, fazendo parte de uma estratégia dos EUA de conter o comunismo que rondava a Europa, assim como de impedir que os países europeus se fechassem sobre si mesmos. O regionalismo emergente saía do quadro multilateralista definido em Genebra por ocasião dos encontros do Gatt.

As posições entre os países europeus eram incompatíveis umas com as outras, resultando em duas direções diferentes: um projeto mais ambicioso (1957) de formar uma Comunidade Econômica Européia (CEE) e um mais modesto (1959) de formar a Associação Européia de Livre Comércio (AELC). Os dois projetos se distinguiam, principalmente, pelo fato de o primeiro ser antes de tudo político, enquanto o segundo era um projeto econômico de inspiração mais liberal ${ }^{9}$. Embora fossem distintos, ambos partilhavam de uma mesma preocupação: a posição da Europa num mundo polarizado pelos EUA e União Soviética.

A criação da CEE irá servir de modelo catalisador e inspirador para a América Latina, cujo primeiro acordo de integração, a Associação LatinoAmericana de Livre Comércio (Alalc), data de 1960. No entanto, conforme se verá adiante, as propostas de integração latino-americanas guardarão uma certa originalidade em relação ao modelo europeu, na medida em que se colocam explicitamente a serviço de um projeto econômico e político de desenvolvimento. 
Em que pesem as diferenças entre os diversos projetos de integração, observa-se, em sua evolução, a presença de três aspectos convergentes. Primeiro, através das discussões sobre os acordos regionais, os debates rapidamente foram deixando o terreno da liberalização propriamente dita e passando para o da integração econômica regional. Segundo, em todos os casos, os acordos tiveram por finalidade última a formação de blocos econômicos homogêneos e de tamanho suficiente para criar uma massa crítica no interior do sistema econômico internacional. Terceiro, a linha de demarcação entre diferentes projetos integrativos se situava menos no fato de implicar países industrializados e países em desenvolvimento, e mais nas diferenças entre os projetos que se traduziam num projeto político explícito e os que se revelavam mais num projeto econômico (Deblock e Brunelle, 1996).

A primeira vaga de regionalismo se desenvolveu dentro de um contexto intervencionista. O Estado e as instituições econômicas internacionais buscaram introduzir uma certa racionalidade num mundo que passara por uma forte depressão nos anos 30 e por uma guerra nos anos 40. Esta lógica engajava os Estados coletivamente a produzir um bem público internacional, que seria o livre comércio. O regionalismo econômico de primeira geração ficará marcado, assim, por quatro características fundamentais: (1) estava voltado mais para uma integração econômica do que para um regionalismo econômico; (2) partilhava de uma visão construtivista de integração inspirada nos parâmetros keynesianos de políticas públicas; (3) deveria permitir a ampliação da margem de manobra dos Estados na condução de suas políticas nacionais, dentro do contexto de liberalização ${ }^{10}$; (4) respondia a objetivos de cunho mais político ou econômico, formando com isso um duplo movimento.

Essa última característica é um dos motivos pelos quais o regionalismo de primeira geração veio a ser ultrapassado. Em decorrência de seu duplo movimento, houve paralelamente o desenvolvimento de instituições comuns de inspiração federalista, por um lado, e a integração econômica e liberalização comercial, por outro. O paralelismo entre os compromissos regionais e os engajamentos em nível internacional acabarão provocando problemas de ordem política e econômica. O convívio com esses problemas só seria possível se fosse mantida uma certa justaposição entre os níveis nacional, regional e internacional, ou, como assinalam Deblock e Brunelle (1996), aplicando-se as idéias de Keynes na política interna e as de Adam Smith na política externa ${ }^{11}$. O regionalismo de primeira geração entrará, dessa maneira, em contradição com a lógica mesma da integração dos mercados em escala mundial.

Marcados pela crise do Estado providência, os anos 70 assistirão à ascensão dos liberais não-intervencionistas, denominados de neoliberais. Fazendo escola na Universidade de Chicago, onde lecionou, Friedrich Hayek receberá em 1974 o Prêmio Nobel de Economia, passando a ser um dos principais mentores do governo Ronald Reagan. Pouco depois, principalmente a partir dos anos 80, a globalização dos mercados virá a ser um dado incontornável, minando o compromisso histórico 
sobre o qual havia sido construída a ordem do Pós-guerra. Os parâmetros da política econômica serão, a partir de então, definidos em termos de competitividade e não mais em termos de progresso econômico e social. É uma outra visão do papel do Estado face à sociedade civil que se coloca. De sua parte, o perigo do comunismo deixará de existir nos anos 90, não se justificando mais o tripartismo.

David Harvey (1996) denomina essa nova situação de "acumulação flexível”. Ela se apóia na flexibilidade dos processos e dos mercados de trabalho, bem como dos produtos e padrões de consumo. Caracteriza-se pelo surgimento de setores de produção inteiramente novos, maneiras novas de fornecimento de serviços financeiros, novos mercados e, sobretudo, taxas altamente intensificadas de inovação tecnológica e comercial ${ }^{12}$.

Esse novo contexto possibilitará a passagem para uma nova forma de regionalismo econômico, chamada de deep integration. Agora, busca-se mais uma integração em profundidade das atividades das empresas no interior dos espaços cobertos pelos acordos assinados, do que simplesmente um incremento das trocas comerciais. Trata-se menos de um projeto político do que de uma forma de permitir aos Estados melhor realizarem seus objetivos perante a cena da economia internacional. A segurança dentro do contexto econômico internacional passa a ser uma preocupação maior. Como sublinham Deblock e Constantin (2000), o objetivo dos Estados signatários desses novos acordos é duplamente securitário: primeiramente para as empresas, criando um ambiente normativo propício para o desenvolvimento de suas atividades transfronteiriças; em segundo lugar para os Estados em si, na medida em que é também, e paralelamente ao primeiro objetivo, uma forma de melhor coordenar o seu ambiente internacional. As características do regionalismo de segunda geração são mais evidentes no Nafta e na proposta da Alca (Deblock e Brunelle, 1999) do que na União Européia e no Mercosul.

Sendo esses os desdobramentos verificados na ordem econômica internacional a partir do fim da Segunda Guerra Mundial, cabe agora indagar de que forma a América Latina se posicionou durante esse período. A resposta a essa indagação nos ajudará a compreender melhor o contexto em que o Mercosul surge.

\section{América Latina: da substituição de importações à abertura ao mercado mundial}

A Conferência de Bretton Woods ficou mundialmente conhecida pela rivalidade entre o Plano Keynes e o Plano White ${ }^{13}$. Um representava os interesses da Inglaterra, que perdia sua hegemonia. O outro, os interesses dos EUA, potência emergente no cenário do Pós-guerra. A principal diferença entre os planos era que Keynes defendia a implantação de apenas uma agência internacional e a criação de uma nova moeda com peso internacional (bancor), enquanto White se voltava 
para a criação de duas agências internacionais - um fundo monetário e um banco para a reconstrução - e a fixação de paridade cambial ao dólar. Sagrando-se vencedora a proposta americana, foram criados o FMI e o Bird.

Contudo, o que quase todos os autores deixam de historiografar é que, não apenas dois, mas três projetos estavam em disputa no encontro de Bretton Woods. O terceiro deles, o Plano Suárez, representava os interesses dos países do Terceiro Mundo, em especial dos latino-americanos ${ }^{14}$. É importante lembrar que dos 44 países participantes em Bretton Woods 19 eram da América Latina. O que reivindicavam esses países?

Na verdade, tanto o Plano Keynes quanto o Plano White estavam preocupados, principalmente, com a reconstrução dos países destruídos pela guerra e com a estabilização monetária. Os países latino-americanos não tinham sido afetados diretamente pelo conflito, a ponto de necessitarem do benefício dos programas de reconstrução. Portanto, para eles as novas instituições internacionais deveriam se voltar não somente à reconstrução, mas igualmente ao desenvolvimento.

Embora sua representação fosse quase a metade do total de participantes, a única alteração lograda por esses países na conferência, ainda assim com certa resistência, foi o compromisso de o banco recém-criado atuar na questão do desenvolvimento. Na prática, no entanto, houve quase que somente a mudança de nome do banco, que passou de Banco Internacional de Reconstrução e Fomento a proposta original - para Banco Internacional de Reconstrução e Desenvolvimento, ficando a América Latina à margem da ordem econômica mundial que surgia ${ }^{15}$. Ela se voltará então para dentro de si mesma e, por meio da Comissão Econômica para a América Latina (Cepal), se concentrará em seu programa de desenvolvimento baseado na industrialização por substituição de importações.

Criada em 1948, no âmbito das Nações Unidas, a Cepal ${ }^{16}$ vai abrigar o projeto de desenvolvimento da América Latina, o qual não havia encontrado espaço dentro da ordem que se estabelecia no Pós-guerra. Tendo à frente o intelectual argentino Raúl Prebisch, a Cepal se diferenciará das demais comissões econômicas regionais da ONU pela originalidade de suas propostas ${ }^{17}$. Prebisch defendia a tese do nacionalismo econômico e a estratégia do desenvolvimento por substituição de importações. A idéia central era que o livre comércio imposto aos países menos desenvolvidos fazia crescer a sua dependência vis-à-vis a produção e exportação dos recursos naturais não transformados. A imposição de barreiras às importações de produtos manufaturados e o desencadeamento de um desenvolvimento industrial endógeno colocavam-se assim como a única forma para romper o círculo vicioso.

Essa estratégia prevalecerá no interior da Cepal, influenciando a maioria dos governos latino-americanos. Os Estados vão se envolver na economia de modo a favorecer o desenvolvimento do mercado interno e a encorajar a produção local, fazendo uso, notadamente, do protecionismo (Cepal, 1998). 
A estratégia de industrialização por substituição de importações já havia sido adotada por diversos países nos anos 30, durante a Depressão. Todavia, ela será retomada e intensificada nos países latino-americanos, atingindo seu auge na década de 1950, até ser abandonada completamente na década de 1990. Essa estratégia pode ser entendida como um processo de desenvolvimento "fechado" e reativo às restrições do comércio exterior (Tavares, 1978), em que a dinâmica substitutiva consiste na forma como a economia reage aos estrangulamentos sucessivos de pagamentos. Através da compressão progressiva da lista de importações, a industrialização passaria dos setores de instalação fácil, pouco exigentes em matéria de tecnologia, capital e escala, a segmentos cada vez mais sofisticados e exigentes (Bielschowsky, 1998).

Não nos cabe aqui encetar uma discussão sobre os diversos motivos que levaram à falência desse modelo, visto não ser esse nosso principal objetivo. Iremos apenas indicar alguns pontos para demonstrar como a América Latina foi abandonando um modelo de desenvolvimento para dentro e se aproximando de um modelo para fora (Cepal, 1994a e 1994b). Essa transformação não se fará sem guardar uma relação direta com as mudanças em suas propostas de integração regional, influenciando, conseqüentemente, o surgimento do Mercosul.

O regionalismo econômico fazia parte da estratégia de desenvolvimento por substituição de importações. Era quase uma condição sine qua non ao processo de industrialização. Os trabalhos iniciais da Cepal destacavam a necessidade de os países da região se agruparem e desenvolverem entre eles as ligações de complementaridade econômica necessárias à implantação de uma estratégia de industrialização por substituição de importações. A idéia lançada nos anos 50 era criar um mercado comum latino-americano. A integração deveria, de um lado, assegurar a sobrevivência do processo de industrialização, contornando o obstáculo que representava o tamanho reduzido do mercado local ${ }^{18}$. De outro lado, deveria diminuir a vulnerabilidade das economias locais em face dos mercados externos, a qual, paradoxalmente, tinha se agravado com a estratégia de industrialização, principalmente devido a um aumento no déficit externo. A integração deveria, enfim, estabelecer, no longo prazo, uma relação mais favorável aos países da América Latina dentro da economia mundial, permitindo-lhes modificar em seu favor, uma vez reestruturadas suas economias, os termos das trocas internacionais (Prebisch, 1988). O regionalismo econômico tinha, com isso, duas direções: a do desenvolvimento através da integração "voltada para o interior”, e a da transformação da relação centro-periferia ${ }^{19}$ (Marcoux, 1996).

Foi com essas bases em mente que os governantes da América Latina assinaram em Montevidéu, em 1960, o acordo criando a Alalc. O objetivo último era promover a livre circulação de "bens e serviços, homens e capitais ... sem nenhum obstáculo, dentro de um vasto mercado comum latino-americano" 
(Marcoux, 1996:4) ${ }^{20}$. Desejava-se estabelecer uma zona de livre comércio em um prazo de 12 anos.

Embora tenha permitido um crescimento do comércio intra-regional em seus primeiros anos, a Alalc mostrou-se aquém das expectativas suscitadas. A disparidade crescente das políticas econômicas dos Estados-membros e a rigidez com que o acordo fora estabelecido estão na raiz dos principais problemas que a conduziram ao fracasso. Ademais, ela guardava várias características do regionalismo de primeira geração, o qual, como já vimos, havia entrado em choque com o movimento mais geral de gobalização econômica, intensificado nos anos 80 .

Paralelamente, inicia-se nos anos 60 um processo de autocrítica no interior da própria Cepal que continua nos anos 70 e 80 quando, com a eclosão da crise do endividamento externo, a paralisação das principais instituições que suportavam o desenvolvimento e a forte queda do ritmo de crescimento, fica evidente que o modelo de desenvolvimento para dentro, ou de substituição de importações, chegara ao seu esgotamento.

Um novo tratado será assinado em 1980, em Montevidéu, criando a Associação Latino-Americana de Integração (Aladi). Conservando o objetivo de longo prazo de criar um mercado comum latino-americano, a Aladi não estabelecerá prazos precisos nem procedimentos fixos. Terá um caráter de maior flexibilidade, se comparada com a Alalc, e tomará mais a forma de um acordo de princípios, servindo como um guarda-chuva para outros acordos bilaterais e sub-regionais, desde que estes estejam abertos à participação dos demais membros. Sua inserção se fará dentro do que a Cepal (1994a) passa a chamar de regionalismo aberto ${ }^{21}$.

Enquanto isso, baseando-se nas medidas de ajustamento estrutural, os países da América Latina vão um após o outro - logicamente que guardando certa singularidade em cada caso - fazer uma virada fundamental, que os conduzirá a orientar cada vez mais suas economias para o exterior. Serão elas liberadas das regulamentações estatais percebidas como obstáculos a tal orientação. A política de ajustamento estrutural será uma prerrogativa do FMI e do Banco Mundial para a outorga dos apoios financeiros necessários aos países latino-americanos para fazer frente ao aprofundamento da crise de suas dívidas externas. É bem verdade que a crise da dívida, assim como os múltiplos problemas com que se defrontaram os países da América Latina nos anos 80, não fizeram mais do que precipitar os acontecimentos. No fundo, eles deveriam se preparar, ou melhor, se ajustar ao novo contexto mundial.

Desta forma, inicia-se no interior desses países um processo que busca, entre outros objetivos, limitar o papel do Estado, desencadear um programa de privatização, diminuir os gastos públicos, eliminar a inflação, estabilizar a moeda, aumentar as exportações e abrir suas economias ao mercado mundial. Dentre os principais países da América Latina, o Chile foi um dos primeiros a aplicar essa política, sendo o Brasil um dos últimos. Estaria aí, nos anos 90, a América Latina 
se inserindo na ordem econômica internacional, revigorada com o fim da Guerra Fria.

Se parece claro que a necessidade, por parte de um número crescente de países latino-americanos, de optar por um modelo de desenvolvimento baseado em premissas neoliberais permite explicar em boa medida a crise do modelo de integração para dentro, a transição para um modelo de desenvolvimento aberto permite, por sua vez, compreender por que nos anos 90 as propostas de integração regional não poderiam ser de outra maneira que não para fora. Existe uma coerência entre o modelo de desenvolvimento adotado pelo conjunto dos países e suas propostas de regionalismo econômico. Mais do que isto, há uma forte complementaridade entre os dois, bastando apenas lembrar que foi no âmbito das negociações do Mercosul que o governo Collor se apoiou para diminuir as barreiras tarifárias do Brasil em relação ao resto do mundo. Os acordos estabelecidos nos moldes do regionalismo aberto vão se inscrever dentro de um processo de liberalização paralelo e complementar ao que é seguido em nível multilateral.

Sob o prisma desse contexto internacional é que o Mercosul emergirá. A Aladi é o âmbito normativo que possibilita a assinatura do Tratado de Assunção em 1991, o qual lhe dá origem. Em suas proposições, o Mercosul buscará agregar os temas do desenvolvimento e da democracia, aliados à preocupação com a modernização competitiva. Constitui-se numa visão distinta daquela derivada do modelo de substituição de importações, de que a Alalc, na sua origem, foi exemplo.

Não obstante, o Mercosul guardará aspectos do regionalismo de primeira geração. Sua inspiração primeira será a União Européia. Embora não tenha criado instituições supranacionais, como por exemplo o Parlamento Europeu, seu modelo de integração atenderá a outras questões que vão além daquelas relativas à segurança para os investimentos, tão presentes no Nafta e na proposta da Alca.

No Mercosul existe uma forte motivação político-estratégica, especialmente por parte do Brasil. Poderíamos dizer, assim, que a sua proposta se insere entre o regionalismo de primeira geração e o de segunda geração, conjugando aspectos de ambos esses regionalismos. Do primeiro podemos destacar a sua tendência federalista e construtivista ${ }^{22}$ de integração, o recurso ao tripartismo ${ }^{23}$, a presença marcante do Estado e a sua motivação político-estratégica. Do segundo destacamos, principalmente, a idéia de um regionalismo aberto, a sua sintonia com a economia mundial, a busca de maior competitividade sob a base de um eixo exportador e de uma liberalização frente às trocas internacionais. Enfim, podemos afirmar que 0 Mercosul é, de certa forma, um projeto original.

\section{Conclusão}

A globalização é um fenômeno complexo que deve ser percebido através de suas diferentes dimensões, contradições e ambigüidades. Após apresentar nossa 
percepção mais geral sobre a globalização e alinhar alguns elementos sobre a regionalização, buscamos analisar a globalização do ponto de vista econômico, numa perspectiva histórica. Vimos que a globalização econômica não é um fenômeno novo. Suas premissas remontam à década de 1940, quando se buscou imaginar um quadro de regulação internacional capaz de assegurar a paz e a prosperidade num mundo que acabara de passar por um segundo conflito generalizado.

A regionalização econômica, por sua vez, é tão antiga quanto a globalização e, diferentemente do que se possa pensar, não é uma conseqüência desta nem uma resposta estrita dos Estados-nações a este movimento. Na verdade, trata-se de dois fenômenos intimamente inter-relacionados. Do ponto de vista histórico, ambos foram marcados pelo contexto internacional que emergiu logo após a Segunda Guerra Mundial e, num segundo momento, pelo fim da Guerra Fria. Do ponto de vista teórico, inspiraram-se inicialmente no keynesianismo, para posteriormente se aproximarem das concepções neoliberais. Tanto as transformações históricas quanto as de cunho teórico provocaram uma mutação nos modelos de regionalismo econômico, podendo-se falar em duas gerações de regionalismo.

A América Latina não deixará de receber influências dessas transformações. Inicialmente, ao se verem à margem da ordem internacional surgida no Pós-guerra, os países latino-americanos buscarão implantar um modelo de desenvolvimento fechado, baseado na industrialização por substituição de importações. A integração regional é vista como uma peça fundamental para o sucesso dessa proposta. Com a criação da Alalc, implanta-se um regionalismo voltado para dentro. Na elaboração dessa concepção de desenvolvimento, a Cepal exercerá um papel fundamental, especialmente as teses defendidas por Raúl Prebisch.

Nos anos 90, com o fim da Guerra Fria e com a ascensão das idéias neoliberais, uma nova proposta de desenvolvimento e de integração emerge, desta vez baseada na liberalização econômica e no modelo de regionalismo voltado para fora ou, segundo a Cepal, um regionalismo aberto. A Aladi substitui a Alalc, servindo de âncora normativa para a criação do Mercosul. Com características do regionalismo de primeira e de segunda geração, o Mercosul é um projeto econômico e político-estratégico que, embora tenha se inspirado no modelo europeu, conserva sua própria originalidade.

\section{Notas}

1 Huntington identifica sete principais civilizações contemporâneas: sínica, japonesa, hindu, islâmica, ocidental, latino-americana e africana.

2 Aos 30 acordos notificados no Gatt de 1992 a 1996 acrescentam-se outros 57 anteriormente existentes (Deblock e Brunelle, 1996). 
3 De acordo com o Protocolo de Ouro Preto de 1994, o Mercosul tornar-se-á uma União Aduaneira plena em 2006.

4 Esta abordagem se distancia das abordagens funcionalista e estruturalista. Os funcionalistas abordam o regionalismo econômico numa perspectiva evolucionista. É a perspectiva que adotam geralmente os economistas e as organizações internacionais, na qual o regionalismo econômico participa do movimento de globalização de duas maneiras: (1) permitindo progredir mais rapidamente uma liberalização das trocas, conduzindo os países ao mercado mundial de maneira seqüencial e passando por fases sucessivas de integração; (2) completando e reforçando o sistema multilateral de cooperação. Já os estruturalistas abordam o regionalismo como uma conseqüência direta das transformações ocorridas no mapa econômico do mundo, causadas, em parte, pela tripolarização das trocas internacionais. A primeira abordagem ignora as considerações geoeconômicas, e a segunda minimiza o papel da articulação entre os níveis regional e mundial da integração econômica (Deblock e Brunelle, 1996).

5 É importante também assinalar a influência de William Beveridge, tendo sido ele um dos primeiros a teorizar a função assistencialista do Estado. Este sociólogo irá fundar sua idéia de assistência na solidariedade nacional.

6 A ONU é constituída de uma Assembléia Geral, um Conselho de Segurança, uma Corte Internacional de Justiça e um Conselho Econômico e Social, além de uma Secretaria e do Trusteeship Council. Desta forma foram institucionalizadas as três principais preocupações, anunciadas anteriormente, na constituição da ONU: a segurança, a justiça e o bem-estar, respectivamente. A idéia da universalidade está representada na Assembléia Geral e a da diferenciação, principalmente, no Conselho de Segurança (Unam, 1995).

7 A proposta inicial era construir um instrumento mundial de cooperação econômica que seria denominado Organização Internacional do Comércio. Mas, ante as tensões entre Leste e Oeste, o projeto derivou na criação do Gatt (Tamames, 1990). Somente depois do fim da Guerra Fria e das evoluções nas negociações da Rodada Uruguai (1986-1994) é que foi possível constituir, em 1995, a Organização Mundial do Comércio (OMC), que veio ocupar o lugar do Gatt.

8 A Oece transformar-se-á, em 1961, num fórum mais amplo: a Organização de Cooperação e de Desenvolvimento Econômico (OCDE).

9 Para os que haviam assinado o Tratado de Paris criando a Comunidade Européia do Carvão e do Aço (Ceca), em 1951, e posteriormente o Tratado de Roma, em 1957, a integração econômica respondia a ordens de preocupação bastante diferentes das que os EUA tinham na época. O mais original na proposta da CEE era o objetivo de implantar instituições comuns e de fazer da integração econômica a base sobre a qual deveria repousar o que mais tarde foi chamado de “Maison Commune”. Paralelamente, a decisão da Inglaterra de não aderir a esse projeto conduziu à criação da AELC (Deblock e Brunelle, 1996).

10 Num primeiro nível, essa ampliação da margem de manobra passava pela transferência de certas prerrogativas às instituições comuns; num segundo nível, passava pela definição de políticas comuns; e, num terceiro nível, passava para formas mais acabadas de integração decorrentes da própria evolução desse processo.

11 O recurso a Keynes em nível da economia nacional aparecia como uma abordagem capaz de garantir a justaposição entre o nacional, o regional e o internacional. Por outro lado, uma das razões da existência da nova ordem econômica internacional era a de reduzir, para não dizer eliminar, a empresa dos Estados-nações sobre o conjunto das relações econômicas internacionais, fossem elas ligadas ao comércio, aos investimentos ou ainda ao câmbio. Todavia, no contexto da época, isto não queria dizer de forma alguma o retorno a uma situação de laisser-faire, mas ao contrário: pretendia construir relações mais seguras da mesma forma que poderiam ser as relações econômicas no interior de cada uma das nações.

12 A análise de Harvey considera que houve uma mudança no regime de acumulação capitalista a partir da intensificação do processo de compressão do espaço-tempo inerente ao capitalismo - 
e vinculado ao modernismo como força cultural -, implicando um encurtamento do tempo e um encolhimento do espaço, que se processam não de modo gradual ou contínuo, mas através de curtas e intensas implosões, durante as quais o mundo muda rapidamente, em direção incerta. Para ele, a última implosão começou em torno de 1970, tendo origem na crise de superacumulação do sistema capitalista sob o regime fordista de produção de massa integrada e vertical. A resposta foi a emergência de um regime flexível de acumulação.

13 Harry D. White era funcionário adjunto do Secretário da Tesouraria dos Estados Unidos. A pedido desta Secretaria, preparou a proposta dos EUA apresentada em Bretton Woods.

14 Eduardo Suárez, então Secretário da Fazenda e Crédito Público do México, foi o chefe da Delegação de seu país na Conferência de Bretton Woods. Três comissões foram constituídas durante a conferência: uma presidida por White, outra por Keynes e uma terceira por Suárez. A Delegação do México apresentara, em julho de 1944, uma declaração intitulada Reconstrucción y desarrollo en pie de igualdad: propuesta de México en Bretton Woods. Esta declaração, que continha a essência do que estamos chamando de Plano Suárez, obteve o apoio de outros países latino-americanos, a exemplo do Brasil, Chile e Venezuela. Sobre o tema pode-se consultar Suárez (1994) e Urquidi (1994).

15 É interessante perceber, no livro de Shotwell (1945), que a América Latina praticamente não é citada, dando sinal de que objetivamente ela não existia na perspectiva do cenário dessa nova ordem mundial.

16 Posteriormente incluirá o Caribe, passando a se chamar Comissão Econômica para a América Latina e o Caribe.

17 Outros nomes importantes que devem ser citados na elaboração do pensamento cepalino em seu início são: Celso Furtado, Osvaldo Sunkel, Aníbal Pinto, José Medina Echavarría, Regino Botti, Juan Noyola Várquez, Jorge Ahumada, entre outros.

18 A baixa demanda, sobretudo nos países menores, dificultava - às vezes impossibilitava - a industrialização nos setores de bens de consumo duráveis e bens de equipamentos.

19 Prebisch apresentava uma visão dualista do mundo marcada pela existência de um "centro" industrializado e de uma "periferia” exportadora de matérias-primas.

20 O autor cita as Nações Unidas.

21 O conceito de regionalismo aberto servirá de ponto de referência central para se relançar a integração regional.

22 No Mercosul é marcante a perspectiva de um processo de evolução seguindo a seqüência: Zona de Livre Comércio, União Aduaneira, Mercado Comum, podendo se chegar a uma União Econômica. Segue a lógica do modelo de regionalismo europeu, diferentemente da proposta do Nafta e da Alca, que não têm esse mesmo tipo de pretensão.

23 O tripartismo é aplicado em alguns órgãos consultivos do Mercosul.

\section{Bibliografia}

BECK, Ulrich. A reinvenção da política: rumo a uma teoria da modernidade reflexiva. In: GIDDENS, Anthony et alii. Modernização reflexiva. São Paulo: UNESP, 1997. 264 p. p. 11-72.

BIELSCHOWSKY, Ricardo. Cincuenta anos de pensamiento en la CEPAL: una resena. In: CEPAL. Cincuenta anos de pensamiento en la CEPAL. Textos Seleccionados, v. 1 e 2, Santiago: Fundo de Cultura, 1998. 947p. p. 9-61.

CEPAL. Cincuenta anos de pensamiento en la CEPAL. Textos Seleccionados, v. 1 e 2, Santiago: Fundo de Cultura, 1998. 947p.

. Regionalismo abierto en América Latina y el Caribe. La integración económica en servicio de la transformación productiva con equidad. 1994a. www.eclac.org/espanol/textosfund/Cepal6.html 
. América Latina y Caribe: políticas para mejorar la inserción en la economia mundial, 1994b. www.eclac.org/espanol/textosfund/Cepal6.html

CHESNAIS, François. A mundialização do capital. São Paulo: Xamã, 1996. 335 p.

DEBLOCK, Christian, BRUNELLE, Dorval. Un régionalisme en trois dimensions: le projet des Amériques. Continentalisation, $n^{\circ}$ 6, Montréal: UQAM/GRIC, 1999. 35p.

. Le régionalisme économique international: de la première à la deuxième génération. Montréal, 1996. www.unites.uqam.ca/gric

DEBLOCK, Christian, CONSTANTIN, Christian. Intégration, régionalisme et régionalisation. Montréal, 2000. www.unites.uqam.ca/gric

DREIFUSS, René Armand. A época das perplexidades. Mundialização, globalização e planetarização: novos desafios. $2^{\mathrm{a}}$ ed. Petrópolis: Vozes, 1997. 350 p.

ERRANDONEA, Alfredo. Hacia una definición operacional del concepto de integración. Revista Argentina de Relaciones Internacionales, Buenos Aires, n 9, p. 86-98, 1977.

FEATHERSTONE, Mike. A globalização da complexidade. Pós-modernismo e cultura de consumo. Revista Brasileira de Ciências Sociais, São Paulo, n 32, 1996.

FERNÁNDEZ, Wilson. Mercosul: economía, política y estrategia en la integración. Montevideo: Fundación de Cultura Universitaria, 1992.

GALTUNG, J. A structural theory of integration. Journal of Peace Research, New Jersey, v. $5 n^{\circ} 4$, 1968.

GIDDENS, Anthony. As Consequências da modernidade. São Paulo: UNESP, 1991. 177 p.

GIDDENS, Anthony, BECK, Ulrich, LASH, Scott. Modernização reflexiva. Política, tradição e estética na ordem social moderna. São Paulo: UNESP, 1997. 264 p.

GÓMEZ, José Maria. Globalização da política: mitos, realidades e dilemas. Trabalho apresentado no Congresso da ANPOCS, Caxambu, 1997. mimeo, 20 p.

HARVEY, David. A condição pós-moderna. São Paulo: Loyola, 1996. 333 p.

HIRST, Paul, THOMPSON, Grahame. Globalização em questão. Petrópolis: Vozes, 1998. 364 p.

HOBSBAWM, Eric. Era dos extremos. O breve século XX, 1914-1991. $2^{\text {a }}$ ed., São Paulo: Companhia das Letras, 1999. $598 \mathrm{p}$.

HUNTINGTON, Samuel. O choque de civilizações e a recomposição da ordem mundial. Rio de Janeiro: Objetiva, 1997. 455 p.

KEYNES, John Maynard. Essais sur la monnaie et l'économie. Paris: Payot, 1978. 143 p.

MARCOUX, Fanny. Intégration économique et régionalisme ouvert en Amérique Latine: des accords de Montevideo au Sommet de Miami. Continentalisation, $\mathrm{n}^{\circ} 1$, Montréal: UQAM/ GRIC, 1996. 24 p.

NYE, Joseph. Peace in parts: integration and conflict in regional organisations. Boston: Little Brown, 1971.

OMAN, Charles. Globalisation et régionalisation: quels enjeux pour les pays en développement? Paris: OCDE, 1994. 152 p.

ORTIZ, Renato. Mundialização e cultura. São Paulo: Brasiliense, 1996. 234 p.

PREBISCH, Raúl. Cinq étapes dans ma réflexion sur le développement. In: MEIER, Guy, SEERS, Denis. Les pionniers du développement. Paris: Econômica, 1988. 376 p. p. 187-223.

SANTOS, Boaventura de Souza. Pela mão de Alice. O social e o político na pós-modernidade. $3^{\mathrm{a}}$ ed. São Paulo: Cortez, 1997. 348 p.

SHOTWELL, James. La grande décision. New York: Bretano’s, 1945. 436 p.

SUÁREZ, Eduardo. La conferencia internacional de Bretton Woods de 1944. Comercio Exterior, México, v. 44, nº 10, p. 848-852, 1994.

TAMAMES, Ramón. Estructura económica internacional. México: CONACULTA/Alianza editorial, 1990. 256 p.

TAVARES, Maria da Conceição. Da substituição de importações ao capitalismo financeiro. Ensaio sobre a economia brasileira. $7^{\mathrm{a}}$ ed. Rio de Janeiro: Zahar, 1978. 263 p. 
UNAM. 50 anos de las Nacíones Unidas. Relações Internacionais, México, nº 65, p. 1-106, 1995. URQUIDI, Victor. Bretton Woods: un recorrido por el primer cincuentenario. Comercio Exterior, México, v. 44, nº 10, p. 838-847, 1994.

VIOLA, Eduardo, OLIVEIRA, Alejandro. Globalização, sustentabilidade e governabilidade democrática no Brasil. In: TRINDADE, Antônio Cançado, CASTRO, Marcus Faro de (Orgs.). A sociedade democrática no final do século. Brasília: Paralelo 15, 1997. 255 p. p. 179-254.

\section{Resumo}

O objetivo deste artigo é compreender o contexto internacional que possibilitou a criação do Mercosul e as condições que favoreceram a definição de seu modelo. Se por um lado esse contexto foi marcado pela globalização, por outro a evolução do regionalismo econômico deixará fortes traços no formato da integração dos países do Cone Sul. As transformações mundiais marcadas pela nova ordem internacional do Pós-guerra e, posteriormente, pelo fim da Guerra Fria não deixarão de influenciar a América Latina. Através de uma abordagem histórico-analítica, os autores buscam mostrar que o Mercosul adotou características de duas gerações distintas do regionalismo, como resultado de uma experiência histórica particular.

\section{Abstract}

This article analyzes the international context which allowed the creation of the Southern Common Market (Mercosur) and the conditions which generated the definition of its model. If, on one hand, globalization had an impact on this context, on the other, the evolution of economic regionalism will strongly influence the type of integration of Mercosur countries. The world transformations, linked to the Post War new international order and to the end of Cold War, will influence Latin America. Through an historical and analytical approach, the authors show that Mercosur adopted features of two different generations of regionalism, as a result of a specific historical experience.

Palavras-chave: Mercosul. Ordem econômica internacional. Globalização, Regionalização.

Key words: Mercosur. International economic order. Globalization. Regionalization. 